\title{
Indução da lactação em mulheres nuligestas: relato de experiência
}

Luciane Cristina Rodrigues Fernandes ${ }^{1}$ (i) Clara Fróes de Oliveira Sanfelice ${ }^{1}$ (1) Elenice Valentim Carmona ${ }^{1}$ (D)

1. Universidade Estadual de Campinas, Faculdade de Enfermagem. Campinas, SP, Brasil.
Autor correspondente:

Luciane Cristina Rodrigues Fernandes.

E-mail: fernandesIcr@gmail.com

Recebido em 17/03/2021.

Aprovado em 27/10/2021.

DOI:https://doi.org/10.1590/2177-9465-EAN-2021-0056

\section{Lactation induction in women who never got pregnant: experience report Inducción de la lactancia en mujeres nuligestas: informe de experiencia}

\section{Resumo}

Objetivo: relatar a experiência de indução da lactação em nuligestas realizada por enfermeira consultora em aleitamento. Método: relato de experiência. O processo de indução láctea foi realizado com três mulheres por motivo de gestação em útero de substituição e relacionamento homoafetivo. Resultados: todas perceberam o aumento de tamanho e a sensibilidade nas mamas, bem como apresentaram secreção láctea. No entanto, a continuidade da amamentação foi diferenciada entre elas. A primeira não recebeu apoio de profissionais de saúde no contexto de pós-parto hospitalar, nem em casa, e não deu continuidade à amamentação. $A$ segunda recebeu apoio da equipe do hospital e da parceira, amamentando por três meses. A terceira, com o apoio da parceira, amamentou por dois meses, mas interrompeu por sentir-se inibida por familiares. Conclusão e implicações para a prática: a técnica de indução é capaz de desencadear a produção láctea. Já o processo de amamentação só se estabeleceu mediante a associação com a rede de apoio, o acolhimento, o incentivo da equipe de saúde e o olhar integral à mulher e sua família. Dessa forma, o cuidado de Enfermagem na indução láctea não deve focar apenas no manejo da indução, mas transcender o aspecto técnico, o que se mostra como fundamental para a proteção, o estabelecimento e a continuidade da amamentação.

Palavras-chave: Lactação; Aleitamento materno; Minorias sexuais e de gênero; Homossexuais femininas; Mães substitutas.

\section{Abstract}

Objective: to report the experience of lactation induction in women who never got pregnant by a lactation consultant nurse. Method: experience report. The process of lactation induction was performed with three women due to surrogate pregnancy and homosexual relationships. Results: all noticed an increase in the size and sensitivity of the breasts, as well as milk secretion. However, the continuity of breastfeeding was different between them. The first did not receive support from health professionals in the postpartum hospital setting, nor at home, and did not continue breastfeeding. The second received support from the hospital staff and her partner, breastfeeding for three months. The third, with the support of her partner, breastfed for two months, but stopped because she felt inhibited by family members. Conclusion and implications for practice: the induction technique is capable of triggering milk production. However, the breastfeeding process was only established through the association with the support network, the reception, the encouragement of the health team, and the comprehensive view of the woman and her family. Thus, nursing care in lactation induction should not focus only on the management of induction, but transcend the technical aspect, which is essential for the protection, establishment, and continuity of breastfeeding.

Keywords: Lactation; Breast Feeding; Sexual and Gender Minorities; Homosexuality, Female; Surrogate Mothers.

\section{Resumen}

Objetivo: reportar la experiencia de inducir la lactancia en nuligestas realizada por una consultora de enfermería en lactancia materna. Método: relato de experiencia. El proceso de inducción de la leche se realizó con tres mujeres por embarazo en útero de reemplazo y relación homoafectiva. Resultados: todas notaron el aumento de tamaño y la sensibilidad en las mamas, además de presentar secreción de leche. Sin embargo, la continuidad de la lactancia materna se diferencia entre ellos. La primera no recibió apoyo de los profesionales de la salud en el contexto posparto hospitalario, ni en el domicilio, y no continuó con la lactancia. La segunda recibió apoyo del personal del hospital y su pareja, amamantando durante tres meses. La tercera, con el apoyo de su pareja, amamantó durante dos meses, pero la interrumpió porque se sentía inhibida por familiares. Conclusión e implicaciones para la práctica: la técnica de inducción es capaz de desencadenar la producción de leche. El proceso de lactancia materna en cambio, solo se estableció a través de la asociación con la red de apoyo, la acogida, el estímulo del equipo de salud y la mirada integral a la mujer y su familia. Así, el cuidado de Enfermería en la inducción de la leche no debe enfocarse solo en e manejo de la inducción, sino trascender el aspecto técnico, que se muestra fundamental para la protección, el establecimiento y la continuidad de la lactancia materna.

Palabras clave: Lactancia; Amamantamiento; Minorías sexuales y de género; Homosexuales femeninas; Madres sustitutas. 


\section{INTRODUÇÃO}

Amamentar é mais do que o ato de nutrir. É um processo dinâmico de interação mãe-bebê que proporciona segurança alimentar, promove saúde e bem-estar, em curto e longo prazos, e é capaz de impactar o desenvolvimento cognitivo e emocional de $a m b o s^{1-4}$.

A Indução da Lactação (IL) é um processo pelo qual uma mulher não puerperal é estimulada para que suas mamas estejam, fisiologicamente, aptas para a lactação. Esta técnica é usada por mulheres que desejam amamentar um bebê adotado ou no caso de bebês gerados por meio da chamada gestação de substituição, que, no Brasil, também é denominada como útero de substituição ${ }^{5}$. Ou seja, uma situação na qual se estabelece um acordo em que uma mulher fica grávida e dá à luz a uma criança que será assumida como filho por outra pessoa ou casal. Outra possibilidade é a amamentação por mulheres que tiveram seus filhos gestados por suas parceiras ${ }^{6}$ em relacionamentos homoafetivos.

A gravidez por útero de substituição é uma técnica de reprodução assistida que envolve a doação temporária do útero por outra mulher quando a gravidez não é possível ${ }^{7}$. A mulher que optar por ser mãe via gravidez por útero de substituição não será exposta aos hormônios lactogênicos da gravidez, assim, a díade mãe-filho pode não desfrutar dos benefícios da amamentação após o nascimento. No entanto, devido à indução bem-sucedida da lactação em mães por adoção ${ }^{6,8}$, tem havido interesse em testar a viabilidade desta intervenção em mães de barriga de aluguel ${ }^{7}$.

Além dos aspectos fisiológicos, o estabelecimento e a continuidade da amamentação são influenciados por diversos fatores como a idade materna, a escolaridade, os aspectos emocionais, os fatores culturais, econômicos, bem como o apoio de familiares, amigos e profissionais da saúde ${ }^{2}$. Tais fatores podem interferir nas atitudes e no conhecimento da mãe sobre a amamentação, bem como em sua autoconfiança, influenciando a continuidade ${ }^{9}$.

O ato de amamentar é considerado natural e fisiológico, porém, sofre influência de vários fatores, como mencionado. Além disso, depende do aprendizado que mãe e filho desenvolvem juntos. Assim, podem ser vivenciadas dificuldades, principalmente, nos primeiros dias ${ }^{09}$. Neste sentido, a jornada para a amamentação por meio da lactação induzida também se mostra repleta de desafios e medos ${ }^{5}$.

Dentre os profissionais de saúde, os de Enfermagem são aqueles com maiores oportunidades de interação com mãe e filho e de influência nesse contexto. Existem numerosas formas com as quais os membros da equipe de Enfermagem podem oferecer suporte para as mulheres em processo de amamentação, o que não se limita a apenas auxiliar a alimentação do bebê por meio da mama ${ }^{10}$. Também são imprescindíveis: um processo educativo sobre a relevância da amamentação; estratégias para a manutenção da produção láctea; informações sobre a extração manual do leite ou com bomba extratora; o oferecimento de folhetos educativos, bem como a identificação na família de pessoas que possam auxiliar a mulher ${ }^{11}$.

Assim, é premente que a equipe de Enfermagem e todos os profissionais de saúde que atuam em alojamento conjunto e em diversos contextos em que a amamentação ocorre adquiram conhecimento teórico e prático de forma a oferecer suporte efetivo para o sucesso da amamentação ${ }^{09}$, incluindo o processo de IL.

Ao entender que a amamentação é uma prática multifatorial, faz-se necessária a capacitação dos profissionais que atuam na área, assim como o compartilhar de experiências sobre temas que ainda não foram investigados com métodos robustos de pesquisa. Nesta perspectiva, o objetivo deste trabalho é relatar a experiência de indução da lactação, realizada por uma enfermeira obstetra, consultora em aleitamento materno, junto a três mulheres em diferentes contextos. Espera-se contribuir para reflexões acerca do tema, entendendo que não basta apenas o direcionamento em relação à técnica, mas contemplar o acolhimento individual, o olhar integral à mulher e família, além do estabelecimento da rede de apoio.

\section{DESCRIÇÃO DA EXPERIÊNCIA}

Esse relato de experiência aborda casos de três mulheres submetidas à IL. O primeiro caso (Caso A) diz respeito à IL em mulher que se tornou mãe via útero de substituição; enquanto o segundo (Caso $B$ ) e terceiro (Caso $C$ ) referem-se à indução em mães que tiveram seus filhos gestados por suas parceiras, em relacionamentos homoafetivos, sendo que, em um dos casos, a gestação foi gemelar. Devido a tratar-se de um relato de experiência, não houve submissão para a avaliação do Comitê de Ética em Pesquisa. No entanto, os preceitos éticos presentes nas normativas de pesquisas científicas que envolvem seres humanos foram respeitados e assegurou-se o sigilo quanto à identidade dos envolvidos.

Para as três mulheres, foi aplicado o protocolo de indução láctea desenvolvido por Newman e Goldfarb ${ }^{12}$. No primeiro e segundo casos, o acompanhamento ocorreu por três meses que antecederam o nascimento dos bebês e utilizou-se o protocolo regular de IL (Figura 1). No terceiro, o acompanhamento foi por apenas um mês com a bebê já nascida há cinco meses. Por isso, foi utilizado o protocolo acelerado (Figura 2).

Esses protocolos utilizam pílula combinada de progesterona e estrogênio, galactogogos (domperidona) e estímulo mamário manual ou por bomba extratora de leite. Para todos os casos, houve a participação de um médico obstetra como responsável pela prescrição dos medicamentos.

O protocolo regular de IL é aplicado quando há tempo hábil para a sua execução. Apresenta melhores resultados, sendo associado à maior possibilidade de aleitamento exclusivo em comparação ao acelerado ${ }^{12}$.

Ao considerar o protocolo acelerado de IL, a produção láctea geralmente é menor, comparativamente com o protocolo regular, mas pode ter papel significativo para a produção láctea nos casos em que não há tempo suficiente para a aplicação do protocolo regular ${ }^{12}$. 


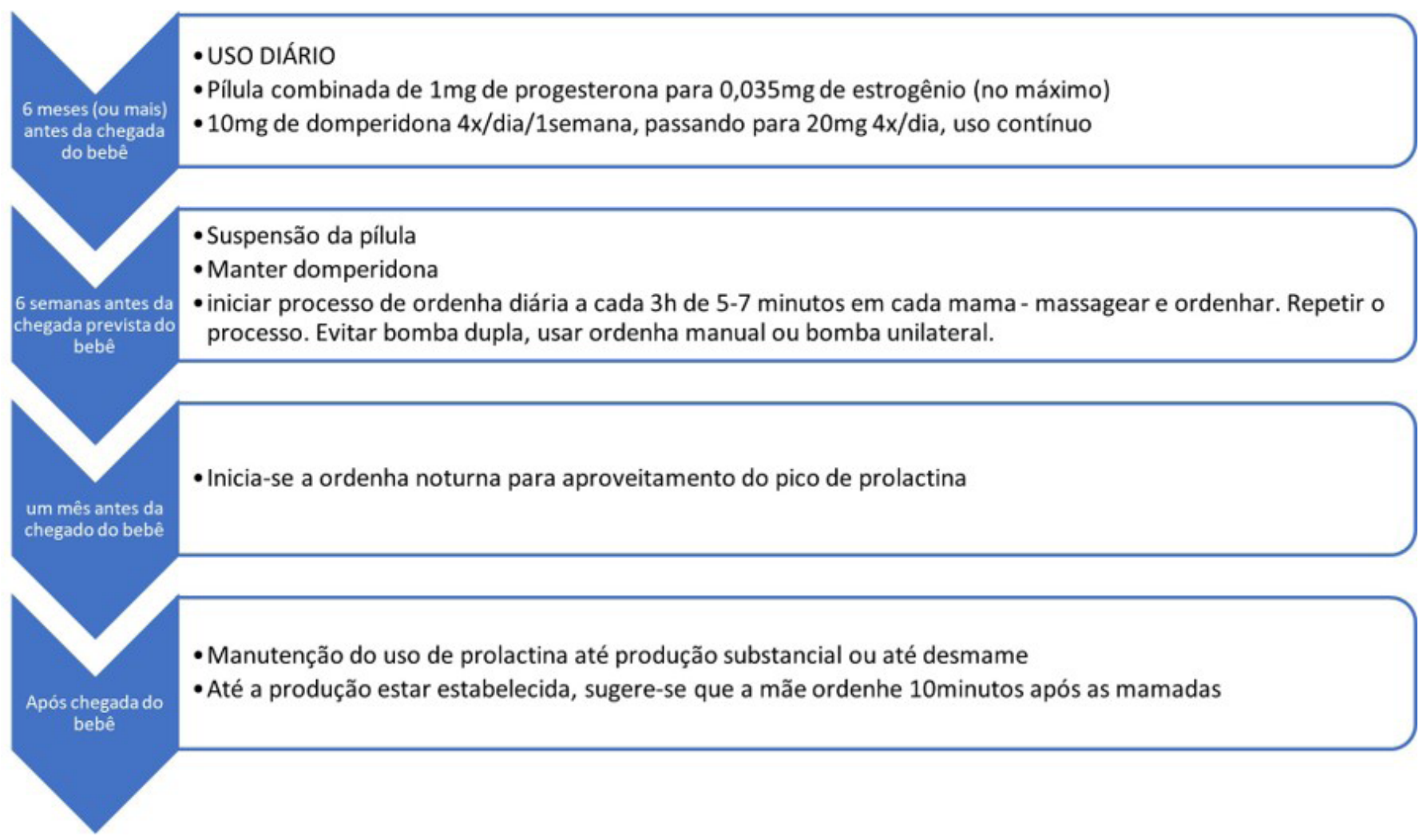

Figura 1. Protocolo regular de indução à lactação ${ }^{12}$.
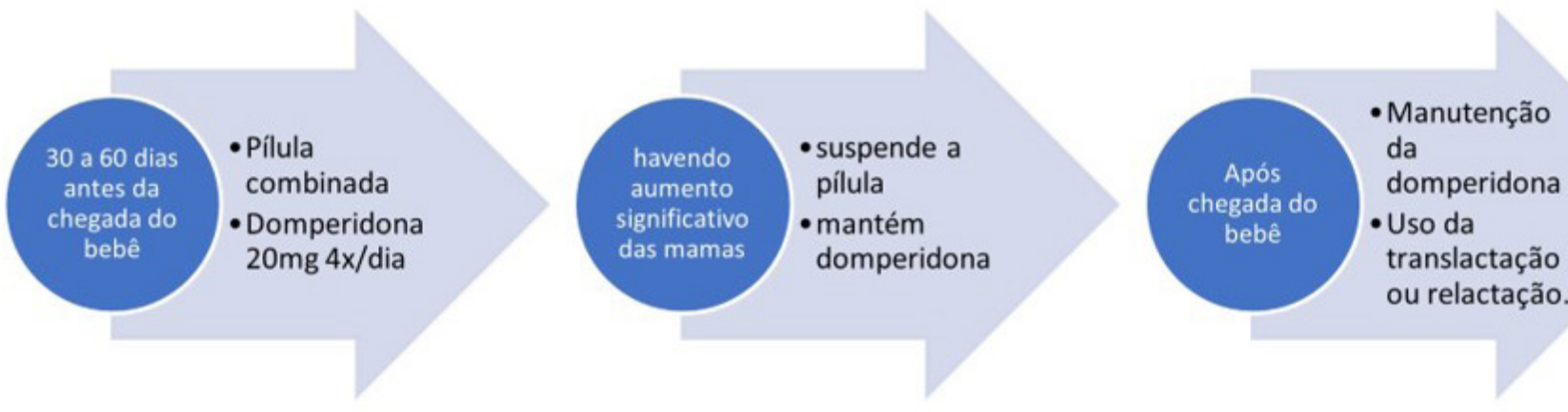

Figura 2. Protocolo acelerado de indução à lactação ${ }^{12}$.

Os três casos foram atendidos pela mesma enfermeira obstetra, tratando-se de três nuligestas e, portanto, sem histórico em amamentação. Ao término do protocolo, todas perceberam o aumento no tamanho das mamas, maior sensibilidade mamária e apresentaram secreção láctea. A seguir, são descritas as experiências junto aos Casos $A, B$ e $C$.

Quanto à indução no Caso $A$, os atendimentos ocorreram em consultório, quinzenalmente, para a orientação e o acompanhamento da evolução. A mulher utilizou bomba extratora de leite elétrica bilateral, cedida pela enfermeira que a acompanhou, para o estímulo mamário, o que era feito a cada três ou quatro horas ao longo do dia, mais duas vezes de madrugada quando ela acordava. Fez acompanhamento médico para a utilização de galactagogo (domperidona) e da pílula hormonal segundo o protocolo mencionado. Esse processo foi acompanhado por três meses. A técnica para a utilização da bomba extratora foi orientada e supervisionada, em seu primeiro uso, pela enfermeira. Nas duas primeiras semanas, a mulher apresentou queixa de sensibilidade mamária, principalmente na região areolomamilar. Nesse momento, foram feitas novas orientação e supervisão 
quanto ao uso da bomba elétrica. Apesar do incômodo relatado, a mulher teve boa aceitação do protocolo sugerido e seguiu-o, mostrando-se bem vinculada ao protocolo proposto. Em nenhum momento, apresentou queixas relacionadas aos efeitos colaterais das medicações.

O Caso B, assim como o anterior, foi acompanhado em consultório, quinzenalmente, utilizando o mesmo modelo de bomba extratora de leite, também cedido pela profissional que a acompanhava. Assim como o anterior, esse processo também foi acompanhado por três meses. A técnica para a utilização da bomba extratora também foi orientada e supervisionada. Nesse caso, a mulher tinha grande sensibilidade na região areolomamilar durante o uso da bomba. Houve supervisão a respeito e novas orientações foram dadas quanto ao uso da bomba elétrica. Devido a apresentar muita sensibilidade, a frequência do estímulo nas mamas foi de três a quatro vezes ao longo do dia e apenas uma vez pela madrugada. Essa mulher experienciou sensações descritas por ela como "tensão pré-menstrual" e que se sentia grávida e hormonalmente instável como sua companheira. Referia alegria por sentir-se assim, pois podia dividir, com a parceira, a sensação das oscilações hormonais. A frequência de estímulo mamário não seguiu, rigorosamente, o protocolo proposto, mas fez uso das medicações conforme proposto.

No Caso C, a mãe decidiu por induzir a lactação quando a sua filha já tinha quase cinco meses de vida e, para esse caso, foram feitas visitas domiciliares semanalmente e essa mãe optou por não fazer uso de pílulas hormonais, mantendo apenas o estímulo mamário, com o mesmo modelo de bomba extratora cedido pela enfermeira que a acompanhava, quatro vezes ao longo do dia, de uma a duas vezes durante a madrugada, além do uso do galactagogo (domperidona) segundo o protocolo mencionado. A mãe que gestou voltaria ao trabalho quando a filha estivesse com seis meses de vida e esse foi o principal motivo que a levou a buscar pela IL. Frente ao tempo limitado, optou-se pelo "protocolo acelerado" conforme a figura 2. Em comum com as demais mulheres, essa também apresentou sensibilidade mamária, principalmente na região areolomamilar. $\mathrm{O}$ uso da bomba extratora foi orientado e supervisionado. Com a presença da queixa de sensibilidade, foram feitas novas abordagem da técnica e reorientação a respeito. Devido à sensibilidade, a mulher optou por diminuir o número de estímulos ao longo do dia. A escolha por não usar hormônio foi baseada em experiências negativas vividas.

Nos casos A e B, as mulheres apresentaram gotas de secreção láctea ao utilizarem a bomba extratora ao término do primeiro mês de indução. Ao final do segundo mês, era possível visualizar maior volume drenado e, antes do terceiro mês de acompanhamento, o volume aumentou significativamente. Não houve um padrão específico no volume de leite extraído por elas, sendo que ele variou de dez a $30 \mathrm{ml}$ em diferentes momentos ao longo dos dias. No Caso C, a mulher apresentou gotas de leite durante o uso da bomba extratora após três semanas do início da IL. Como a filha já mamava na mãe biológica, ela deixou de usar a bomba extratora e passou a oferecer a mama diretamente à bebê nos momentos em que desejava fazer estímulo ou quando a filha buscava por sucção não nutritiva.

A continuidade do processo de amamentação sofreu a interferência de aspectos multifatoriais não abordados durante o processo de assistência à IL. No Caso $\mathrm{A}$, devido à particularidade da gestação por útero de substituição, a mulher sempre fez acompanhamento psicológico durante todo o processo. Ela esteve presente no nascimento de seu filho, porém, não realizou contato pele a pele ou amamentação na primeira hora de vida, uma vez que a equipe do hospital não possibilitou essa vivência. Em alojamento conjunto, permaneceu com o filho, mas relatou que, novamente, a amamentação não foi estimulada. Somado a isso, recebeu orientações sobre a alimentação com fórmula infantil em mamadeira e não houve o oferecimento da possibilidade de realização da translactação. Durante todo o período de internação, segundo sua percepção, a equipe não prestou assistência à amamentação. A mulher referiu que tentou sozinha colocá-lo na mama, com dificuldade e sem ajuda para fazê-lo. Também referiu que, após a alta hospitalar, não recebeu apoio familiar e foi desestimulada por seu companheiro a buscar atenção profissional para mediar a situação.

No Caso B, antes do nascimento, as mães construíram um plano de parto e de amamentação com a descrição de suas intenções sobre o parto e o pós-parto, bem como o estímulo à amamentação. Esse documento foi apresentado previamente ao hospital antes do nascimento das filhas gemelares. Nele, constava a vontade das duas mães em fazerem o contato pele a pele $e$ amamentarem na primeira hora de vida. Também foi firmado que era consenso entre as duas mães que a amamentação também fosse realizada pela mãe não biológica. Para fundamentar tal solicitação, anexaram-se, ao plano, os registros fotográficos da extração de leite e os exames sorológicos que comprovaram a elegibilidade de ambas para a amamentação.

No dia do nascimento, o plano de parto foi respeitado. Em alojamento conjunto, houve a prescrição de fórmula, porém, as mães optaram por oferecê-la somente após a amamentação em mama materna. Em casa, a família possuía uma rede de apoio estruturada que auxiliava e apoiava a amamentação. A mãe que induziu a lactação amamentou por três meses. $O$ desmame ocorreu devido a lesões mamárias persistentes, sendo esse um dos fatores apontados pela literatura como causa possível de desmame ${ }^{13,14}$

No Caso C, a mãe (não biológica) iniciou a amamentação após o sexto mês de vida da bebê, intercalando a amamentação com a sua parceira, especialmente nos períodos de ausência da mãe biológica. Sabidamente, a quantidade de leite era inferior em relação à de sua parceira, porém, a amamentação foi iniciada junto com a introdução alimentar e estabelecida com sucesso após as refeições e para o conforto da bebê. Neste caso, a amamentação aconteceu por um período de dois meses e foi interrompida devido à mãe que recebeu a IL não se sentir confortável para amamentar em público ou na presença de familiares. 


\section{ANÁLISE DA EXPERIÊNCIA}

\section{Técnica para IL}

O acompanhamento desses três casos confirma que a abordagem tecnicista, sem o acolhimento integral à mulher e aos seus familiares, pode levar à excreção láctea, mas não contempla tudo o que é necessário para o estabelecimento e a continuidade da amamentação.

Cabe, aos sistemas de saúde, muitos dos quais têm uma visão inovadora de saúde pública, desenvolver um modelo simples e de baixo custo de instrumentalização da equipe para fornecer apoio à amamentação, o que elevaria o nível de saúde da população por promover o oferecimento de melhor alimento aos lactentes, assim como o aumento de satisfação das famílias que amamentam ao alcançarem seus objetivos. Além disso, resultaria em maior satisfação da equipe com o seu trabalho, visto que ela almeja fornecer informações e atendimento adequados, mas nem sempre o faz devido ao processo de trabalho, ao dimensionamento de pessoal e à falta de educação continuada sobre o aleitamento materno ${ }^{15}$.

É de suma importância que os profissionais de saúde envolvidos nos cuidados obstétricos e perinatais desenvolvam conhecimento técnico e habilidades para atuar em apoio, promoção e proteção do aleitamento, o que inclui conhecimento sobre a possibilidade de IL para as mulheres que não gestaram seus filhos.

Esse relato de experiência denota tal fragilidade da assistência, que precisa ser mudada para contemplar todas as mulheres que irão precisar da IL. Além disso, verifica-se que as crenças pessoais dos profissionais sobre o quanto uma mulher poderá ter sucesso ou não no estabelecimento e na continuidade da amamentação são limitantes para o sucesso desse processo, impedindo que as famílias recebam o cuidado adequado. Além disso, as experiências descritas demonstram que a equipe de saúde ainda não está preparada para atender às novas conformações familiares. Assim, são temas que devem ser mais abordados na formação dos profissionais e em estratégias de educação continuada.

\section{Rede de apoio e conhecimento de direitos da mulher}

A prática da amamentação e o desmame precoce são o reflexo da conjunção de determinação biológica e condicionamento sociocultural, econômico e político ${ }^{4}$. Ao investigar os fatores que dificultam o aumento das taxas de Aleitamento Materno Exclusivo (AME) e levam ao desmame precoce, a literatura apontou os seguintes fatores: falta de preparo de profissionais de saúde para acolher o aleitamento materno dentro da rotina hospitalar; introdução precoce de fórmula láctea; dor ao amamentar ou presença de lesão mamária; insegurança materna ou experiência pregressa negativa e falta de apoio dos familiares. Além disso, têm-se situações especiais, como a prematuridade e outras condições de saúde, que separam a mãe do recém-nascido ${ }^{13}$.
Como exposto nos casos descritos, diferentes fatores levaram à interrupção da amamentação. No Caso $A$, a falta de preparo dos profissionais e a ausência de respeito aos direitos da mulher no puerpério e de boas práticas na atenção ao nascimento culminaram na falta de oportunidade para que a mãe colocasse seu filho junto à mama e vivenciasse o pele a pele e a amamentação na primeira hora de vida deste último. Esses eventos, comprovadamente, favorecem o sucesso do aleitamento materno ${ }^{1,16}$.

Uma revisão sistemática apontou recomendações que configuram um conjunto de medidas efetivas para o incentivo ao AME intra-hospitalar: contato pele a pele precoce; permanência de mãe e filho em alojamento conjunto; intervenção na dor mamilar durante a amamentação; restrição do uso de suplementação para lactentes; aleitamento materno sob livre demanda e as intervenções educativas por meio de suporte individual e/ou em grupos durante a internação ${ }^{13}$. Assim, além das orientações acerca da técnica da IL, a mulher precisa conhecer e ter acesso a facilitadores do processo de estabelecimento, promoção e proteção do aleitamento.

O plano de parto é a documentação das decisões do casal a respeito do parto e nascimento. Tais decisões são pautadas em possibilidades seguras para o cuidado. Assim, o plano de parto é recomendado pela Organização Mundial de Saúde (OMS) como uma das estratégias para melhorar o nível do atendimento às mulheres e aos recém-nascidos ${ }^{16}$. Nele, pode ser manifestada a vontade da permanência de um acompanhante de acordo com a Lei Federal no 11.108/2005: garante às parturientes direito a acompanhante durante todo o trabalho de parto, parto e pósparto, no Sistema Único de Saúde (SUS), na rede própria ou conveniada, bem como a possibilidade de solicitar que seja aplicada a Lei Estadual (SP) no 15.759/2015, que assegura o direito ao parto humanizado nos estabelecimentos públicos de saúde do Estado e dá outras providências, englobando as boas práticas para o parto e nascimento ${ }^{16}$.

Nesse contexto, o plano de parto é muito mais utilizado com enfoque nas questões relacionadas ao trabalho de parto e parto que em amamentação. Este relato de experiência demonstra a premência de que profissionais e mulheres saibam a relevância de que ele também seja utilizado para determinar as questões relacionadas à amamentação. Além disso, verificou-se que a mulher que apresentou plano de parto teve mais autonomia durante a assistência hospitalar do que as que não o fizeram, o que pode englobar a IL. A compreensão das mulheres acerca desse tema pode diminuir o risco de más práticas relacionadas ao parto e nascimento, bem como garantir seu protagonismo no nascimento e cuidados com o seu filho, como foi vivido pelas mulheres do Caso B.

\section{Paradigmas sociais}

A IL possibilita que mães que não gestaram seus filhos possam amamentar. Desse modo, com o aumento da divulgação dessa técnica, maior número de mulheres que adotam e mulheres homoafetivas poderão usufruir dessa prática mundialmente 
recomendada, o que é relevante também para que mais crianças se beneficiem das inúmeras vantagens do leite humano para o seu crescimento e desenvolvimento, além dos aspectos afetivos.

Para que isso aconteça com maior naturalidade e haja respeito aos desejos da mãe (ou das mães), tanto os profissionais de saúde quanto a sociedade precisarão revisitar e compreender a definição da expressão "amamentação cruzada". A amamentação cruzada refere-se à prática de alimentar um bebê por meio da mama de outra mulher que não a mãe. Ao entender que uma mulher que adota um bebê é sua mãe, assim como as duas mulheres em um casal homoafetivo são mães do mesmo bebê, não haverá qualquer prejuízo ou risco à criança se ela for amamentada pela mãe, seja ela aquela que a gestou ou não.

A imposição de alguns modelos sociais poderá impedir a continuidade da amamentação com consequente infortúnio à saúde infantil. Tais modelos relacionam-se à maior valorização da fórmula láctea e à desvalorização do aleitamento materno. Além disso, relacionam-se ainda com o não acolhimento das vontades maternas, com a imposição das normativas quanto ao que se espera do comportamento feminino e da supremacia do relacionamento heterossexual, visando a suprimir ou a ignorar a liberdade das mulheres e a existência do relacionamento homoafetivo. Essa imposição, por exemplo, fez com que a mulher do Caso $C$ se sentisse extremamente desconfortável ao amamentar a filha em locais em que pudessem ficar expostas ao julgamento social.

Ao entender que o leite materno é o melhor alimento que um bebê pode receber e que amamentar envolve muito mais que nutrição, fazem-se imprescindíveis maior acolhimento e mudança dos paradigmas impostos por uma cultura de consumo e heteronormativa.

\section{Cuidado integral: vislumbrando ir além da técnica}

Cada mulher e família apresentam particularidades que precisam ser compreendidas para que seja ofertada uma assistência individualizada, que contemple o cuidado integral e articule ações de promoção, proteção e apoio ao aleitamento materno. O plano de cuidados estabelecido precisa ser compreendido e fazer sentido para a mulher e a família, mas, principalmente, para a mulher. Além disso, devem-se estabelecer estratégias para a prevenção de problemas que levam ao desmame, como o cuidado das lesões mamiloareolares, entre outras necessidades ${ }^{3}$. As Redes de Atenção à Saúde, independentemente do agente prestador do cuidado ou do local da prestação do serviço, devem estar vinculadas à recuperação das práticas relacionadas ao aleitamento materno de forma que ocorram a remoção de obstáculos e a disseminação de práticas adequadas em prol da amamentação ${ }^{3}$. Aqui, salienta-se a premência do preparo dos profissionais para $\mathrm{o}$ acolhimento de mulheres submetidas à IL ou que dela necessitam, prestando apoio para a manutenção do aleitamento materno. No entanto, como já descrito, ainda existem muitas barreiras para que a mulher usufrua de uma rede de apoio fortalecida e preparada para facilitar a amamentação. O acompanhamento da mulher e de seu filho por consultora em aleitamento materno, desde o momento da alta, pode ser uma das possíveis soluções ${ }^{17}$. Ao pensar nas mulheres que não podem pagar por esse acompanhamento especializado, os profissionais devem estar preparados para realizar esse papel na atenção primária.

Assim, outro aspecto relevante é que as habilidades e o conhecimento em amamentação não podem ser exclusivos de especialistas, considerando-se a relevância de seu impacto na saúde da população. Assim, ao perpetuar-se um acesso díspar à saúde, apenas as famílias com maior poder aquisitivo terão o acompanhamento desse tipo de especialista por terem poder aquisitivo para contratá-lo. Portanto, a formação dos profissionais de saúde deve vislumbrar que a promoção e o apoio à amamentação sejam garantidos no pré-natal, no atendimento hospitalar ao parto, nascimento e puerpério e na continuidade do cuidado em atenção básica à saúde em todos os estabelecimentos vinculados ao SUS. Esses profissionais devem ser instrumentalizados em amamentação para fornecer $o$ atendimento de forma equitativa. Considera-se que elevar os índices de amamentação é uma estratégia em saúde pública, simples e de baixo custo, que proporciona um maior nível de satisfação às famílias, ajudando-as a valorizar esse cuidado à saúde e alcançar suas metas com a prática do aleitamento ${ }^{15}$.

\section{CONCLUSÕES E IMPLICAÇÕES NA PRÁTICA}

A experiência vivenciada pelas três mulheres mostrou que a IL, em nuligestas, é factível e não deve ser vista apenas como a aplicação de técnicas e protocolos de estímulo do tecido mamário. A excreção láctea não define a satisfação ou o sucesso no processo de aleitar nessas mulheres, mas o processo como um todo. Ressalta-se a relevância do oferecimento de esclarecimentos sobre os conceitos relacionados à amamentação e aos direitos das mulheres que amamentam, bem como que os profissionais investiguem suas necessidades de forma individualizada. Além disso, os profissionais devem identificar ainda suas limitações de conhecimento, crenças e valores que podem interferir, negativamente, na assistência e nos índices de aleitamento materno.

O acompanhamento do processo de IL nessas mulheres mostrou que amamentar transcende a ação de nutrir, sendo que a sua continuidade é influenciada por questões de origem multifatorial que devem ser consideradas e incluídas no plano de cuidados. Os profissionais de saúde devem apropriar-se das estratégias da IL, indo além do aspecto técnico da indução, considerando a subjetividade dos envolvidos, contemplando cenários que se tornam cada vez mais presentes como as mães adotivas, os úteros de substituição e os casais homoafetivos.

Nesta perspectiva, a formação profissional básica e a educação continuada devem abranger a IL não apenas em seu manejo técnico, mas auxiliar a mulher na superação de medos, no enfrentamento de desafios, na estruturação de uma rede de apoio para que a vivência do aleitar seja uma experiência satisfatória para a mulher, o bebê e a família. Dado o impacto positivo do aleitamento materno na saúde da população e no estabelecimento 
do vínculo entre mãe e filho, espera-se inspirar outros profissionais a desenvolverem estratégias individualizadas para promovê-lo.

\section{CONTRIBUIÇÕES DOS AUTORES}

Desenho do relato de experiencia. Luciane Cristina Rodrigues Fernandes. Clara Fróes de Oliveira Sanfelice. Elenice Valentim Carmona

Levantamento de informações. Luciane Cristina Rodrigues Fernandes.

Análise da experiencia. Luciane Cristina Rodrigues Fernandes. Clara Fróes de Oliveira Sanfelice. Elenice Valentim Carmona Interpretação. Luciane Cristina Rodrigues Fernandes. Clara Fróes de Oliveira Sanfelice. Elenice Valentim Carmona

Redação e revisão crítica do manuscrito. Luciane Cristina Rodrigues Fernandes. Clara Fróes de Oliveira Sanfelice. Elenice Valentim Carmona

Aprovação da versão final do artigo. Luciane Cristina Rodrigues Fernandes. Clara Fróes de Oliveira Sanfelice. Elenice Valentim Carmona

Responsabilidade por todos os aspectos do conteúdo e a integridade do artigo publicado. Luciane Cristina Rodrigues Fernandes. Clara Fróes de Oliveira Sanfelice. Elenice Valentim Carmona

\section{EDITOR ASSOCIADO}

Beatriz Rosana Gonçalves de Oliveira Toso (1)

\section{EDITOR CIENTÍFICO}

Ivone Evangelista Cabral (1)

\section{REFERÊNCIAS}

1. Victora CG, Horta BL, de Mola CL, Quevedo L, Pinheiro RT, Gigante $\mathrm{DP}$ et al. Association between breastfeeding and intelligence, educational attainment, and income at 30 years of age: a prospective birth cohort study from Brazil. Lancet Glob Health. 2015;3(4):e199-205. http://dx.doi. org/10.1016/S2214-109X(15)70002-1. PMid:25794674.

2. Victora CG, Bahl R, Barros AJ, França GV, Horton S, Krasevec J et al. Breastfeeding in the 21st century: epidemiology, mechanisms, and lifelong effect. Lancet.2016;387(10017):475-90. http://dx.doi.org/10.1016/ S0140-6736(15)01024-7. PMid:26869575.

3. Ministério da Saúde (BR), Secretaria de Atenção à Saúde, Departamento de Ações Programáticas Estratégicas. Bases para a discussão da política nacional de promoção, proteção e apoio ao aleitamento materno [Internet]. Brasília: Ministério da Saúde; 2017 [citado 2021 jan 10]. Disponível em: https://bvsms.saude.gov.br/bvs/publicacoes/ bases_discussao_politica_aleitamento_materno.pdf
4. Venancio SI, Toma TS. Promoção, proteção e apoio ao aleitamento materno: evidências científicas e experiências de implementação [Internet] São Paulo: Instituto de Saúde; 2019 [citado 2021 jan 10]. Disponível em: http://www.saude.sp.gov.br/resources/instituto-de-saude/ homepage/pdfs/49082001internetbx.pdf

5. Farhadi R, Philip RK. Induction of lactation in the biological mother after gestational surrogacy of twins: A novel approach and review of literature. Breastfeed Med. 2017;12(6):373-6. http://dx.doi.org/10.1089/ bfm.2016.0112. PMid:28631931.

6. Wahlert L, Fiester A. Induced lactation for the nongestating mother in a lesbian couple. Virtual Mentor. 2013;15(9):753-6. http://dx.doi. org/10.1001/virtualmentor.2013.15.9.ecas2-1309. PMid:24021102.

7. Zingler E, Amato AA, Zanatta A, Vogt MF, Wanderley MD, Mariani Neto $C$ et al. Lactation induction in a commissioned mother by surrogacy: effects on prolactin levels, milk secretion and mother satisfaction. Rev Bras Ginecol Obstet. 2017;39(2):86-9. http://dx.doi.org/10.1055/s-0037-1598641. PMid:28257588.

8. Wilson E, Perrin M, Fogleman A, Chetwynd E. The intricacies of induced lactation for same-sex mothers of an adopted child. J Hum Lact. 2015;31(1):64-7. http://dx.doi.org/10.1177/0890334414553934. PMid:25311827.

9. Carvalho MR, Gomes CF. Amamentação: bases científicas. $4^{a}$ ed. Rio de Janeiro: Guanabara Koogan; 2017. 554 p.

10. Emídio SCD, Oliveira VRRF, Carmona EV. Mapeamento das intervenções de enfermagem no estabelecimento da amamentação em uma unidade de internação neonatal. Rev Eletr Enferm. 2020;22. http://dx.doi. org/10.5216/ree.v22.61840.

11. Shattnawi KK. Healthcare professionals' attitudes and practices in supporting and promoting the breastfeeding of preterm infants in NICUs. Adv Neonatal Care. 2017;17(5):390-9. http://dx.doi.org/10.1097/ ANC.0000000000000421. PMid:28787301.

12. Newman J, Goldfarb L. Introduction to the protocols for induced lactation Canadian [Internet]. Quebec: Canadian Breastfeeding Foundation; 2000 [citado 2021 jan 10]. Disponível em: https://www. canadianbreastfeedingfoundation.org/induced/regular_protocol.shtml

13. Coca KP, Amir LH, Alves MRS, Barbieri M, Marcacine KO, Abrão ACF. Measurement tools and intensity of nipple pain among women with or without damaged nipples: a quantitative systematic review. $J$ Adv Nurs. 2019;75(6):1162-72. http://dx.doi.org/10.1111/jan.13908. PMid:30407654.

14. Berens P, Eglash A, Malloy M, Steube AM. ABM clinical protocol: persistent pain with breastfeeding. Breastfeed Med. 2016;11(2):46-53 http://dx.doi.org/10.1089/bfm.2016.29002.pjb. PMid:26881962.

15. Eglash A. An alternative strategy to solve the problem of the discontinuity of breastfeeding care. Breastfeed Med. 2016;11(3):153. http://dx.doi. org/10.1089/bfm.2016.0028. PMid:26982551.

16. Ministério da Saúde (BR), Secretaria de Ciência, Tecnologia e Insumos Estratégicos, Departamento de Gestão e Incorporação de Tecnologias em Saúde. Diretrizes nacionais de assistência ao parto normal: versão resumida [Internet]. Brasília: Ministério da Saúde; 2017 [citado 2021 jan 10]. Disponível em: https://bvsms.saude.gov.br/bvs/publicacoes/ diretrizes_nacionais_assistencia_parto_normal.pdf

17. Garner CD, Ratcliff SL, Thornburg LL, Wethington E, Howard CR, Rasmussen KM. Discontinuity of breastfeeding care: "there's no captain of the ship. Breastfeed Med.2016;11(1):32-9. http://dx.doi.org/10.1089/ bfm.2015.0142. PMid:26566010. 